\title{
Validation of the McClear clear-sky model in desert conditions with three stations in Israel
}

\author{
Mireille Lefèvre and Lucien Wald \\ MINES ParisTech - PSL Research University, Sophia Antipolis, Paris, France \\ Correspondence to: Lucien Wald (lucien.wald@mines-paristech.fr)
}

Received: 30 November 2015 - Revised: 18 February 2016 - Accepted: 26 February 2016 - Published: 2 March 2016

\begin{abstract}
The new McClear clear-sky model, a fast model based on a radiative transfer solver, exploits the atmospheric properties provided by the EU-funded Copernicus Atmosphere Monitoring Service (CAMS) to estimate the solar direct and global irradiances received at ground level in cloud-free conditions at any place any time. The work presented here focuses on desert conditions and compares the McClear irradiances to coincident 1 min measurements made in clear-sky conditions at three stations in Israel which are distant from less than $100 \mathrm{~km}$. The bias for global irradiance is comprised between 2 and $32 \mathrm{~W} \mathrm{~m}^{-2}$, i.e. between 0 and $4 \%$ of the mean observed irradiance (approximately $830 \mathrm{~W} \mathrm{~m}^{-2}$ ). The RMSE ranges from 30 to $41 \mathrm{~W} \mathrm{~m}^{-2}(4 \%)$ and the squared correlation coefficient is greater than 0.976 . The bias for the direct irradiance at normal incidence (DNI) is comprised between -68 and $+13 \mathrm{~W} \mathrm{~m}^{-2}$, i.e. between -8 and $2 \%$ of the mean observed DNI (approximately $\left.840 \mathrm{~W} \mathrm{~m}^{-2}\right)$. The RMSE ranges from $53(7 \%)$ to $83 \mathrm{~W} \mathrm{~m}^{-2}(10 \%)$. The squared correlation coefficient is close to 0.6. The performances are similar for the three sites for the global irradiance and for the DNI to a lesser extent, demonstrating the robustness of the McClear model combined with CAMS products. These results are discussed in the light of those obtained by McClear for other desert areas in Egypt and United Arab Emirates.
\end{abstract}

\section{Introduction}

The downwelling solar irradiance observed at ground level on horizontal surfaces and integrated over the whole spectrum (total irradiance) is called surface solar irradiance (SSI). It is the sum of the direct irradiance, from the direction of the sun, and the diffuse, from the rest of the sky vault, and is also called the global irradiance. The SSI is an essential climate variable as established by the Global Climate Observing System in August 2010 (GCOS, 2016). Knowledge of the SSI and its geographical distribution is of prime importance for numerous domains where SSI plays a major role as e.g. weather, climate, biomass, and energy.

A model estimating the SSI under clear sky or cloud-free conditions is called a clear-sky model. Oumbe et al. (2014) have demonstrated that computations of the SSI from satellite images can be approximated by the product of the clearsky SSI and a modification factor due to cloud properties and ground albedo only. Changes in clear-atmosphere properties have negligible effect on this modification factor so that both terms can be calculated independently. These results are im- portant in the view of an operational system as it permits separating the whole processing into two distinct and independent models, whose input variable types and resolutions may be different. This enforces the importance of the availability of an accurate and easy-to-operate model for the assessment of the clear-sky SSI.

The McClear model (Lefèvre et al., 2013) is such a model. It has been designed to benefit from the recent advances on atmosphere composition made in MACC projects (Monitoring Atmosphere Composition and Climate). The latter were preparing the operational provision of global aerosol properties analyses and forecasts together with physically consistent total column content in water vapour and ozone available every $3 \mathrm{~h}$ (Benedetti et al., 2009; Kaiser et al., 2012; Peuch et al., 2009). Such information had not been available so far from any operational numerical weather prediction centre. Since 1 January 2016, the McClear model and its inputs are part of the operational services delivered by the Copernicus Atmosphere Monitoring Service (CAMS) operated by ECMWF on behalf of the European Commission. 
Table 1. Geographical coordinates of the three stations. Period is 2006-2011. All data are coincident. Number of samples is 19849 in $G, B$ and $D$.

\begin{tabular}{lccc}
\hline Station & $\begin{array}{c}\text { Latitude (positive } \\
\text { North, ISO 19115) }\end{array}$ & $\begin{array}{c}\text { Longitude (positive } \\
\text { East, ISO 19115) }\end{array}$ & $\begin{array}{c}\text { Elevation } \\
\text { a.s.1. (m) }\end{array}$ \\
\hline Beer Sheva (BEE) & 31.25 & 34.8 & 195 \\
Sede Boqer (SBO) & 30.905 & 34.782 & 500 \\
Yotvata (YOT) & 29.879 & 35.065 & 66 \\
\hline
\end{tabular}

The CAMS McClear service is available as an interoperable Web processing service (WPS), i.e. an application that can be invoked via the Web and that obeys the OGC (Open Geospatial Consortium) standard for interoperability (Percivall et al., 2011). This service delivers estimates of the global SSI and its direct and diffuse components on horizontal surface as well as the direct SSI at normal incidence, for various durations ranging from $1 \mathrm{~min}$ to 1 month.

Since its inception as a pre-operational service, McClear has been increasingly used by academics and practitioners. A lot of attention is paid to the validation of the estimates provided by McClear. The goal is to better establish the domain of validity of McClear, its qualities and drawbacks, and to bring transparency and confidence in the use of this operational service.

McClear has been previously validated with respect to 1 min measurements of global and direct SSI on horizontal surface from the Baseline Surface Radiation Network (BSRN) collected from 11 sites located throughout six continents (Lefèvre et al., 2013). The relative root mean square error (RMSE) for global SSI and direct SSI depends on the station and ranges respectively between 3 and $5 \%$ of the mean of the measurements for the station, and between 5 and $10 \%$.

This article aims at contributing further to the validation of the McClear model. It focuses on desert conditions encountered in Israel where three close stations measure the global, diffuse and direct SSI. This density of stations permits to study the variability of the performances of McClear in this climate homogeneous area.

\section{Measurements and McClear estimates}

Measurements of the global $G$ and diffuse $D$ SSI and of the beam irradiation received at normal incidence $B_{\mathrm{N}}$ were collected from three stations (Fig. 1 and Table 1) from the Israel Meteorological Service (IMS), the BSRN network and an undisclosed company for the period 2006-2011. The direct SSI $B$ on horizontal surface is computed from the difference $G-D$. Measurements are integrated over $10 \mathrm{~min}$ at Beer Sheva and Yotvata and $1 \mathrm{~min}$ at Sede Boqer which belongs to the BSRN network. 1 min measurements at Sede Boqer were averaged over $10 \mathrm{~min}$ to match the sampling rate of the two other stations. The solar zenith angle $\theta_{\mathrm{S}}$ corresponding to each measurement is computed with the SG2 al-

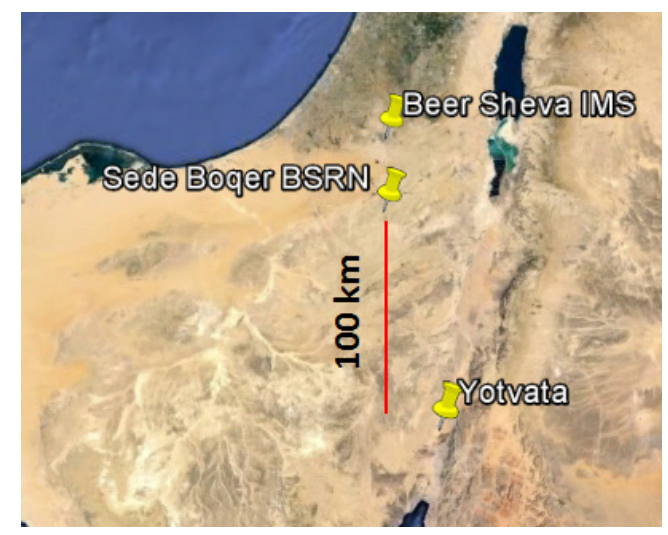

Figure 1. Map of the three stations. The red line is $100 \mathrm{~km}$ in length.

gorithm (Blanc and Wald, 2012). After applying the quality check procedures of Roesch et al. (2011), only the measurements were kept which pass the filters proposed by Lefèvre et al. (2013) to retain reliable clear-sky instants. Finally, only are kept clear-sky instants for which measurements are valid for the three stations simultaneously. The number of samples is 19849 for each station. This last constraint was imposed in order to be able to compare correlation coefficients computed for data sets, whether measurements or estimates, for two stations.

The three stations are fairly close to each other (Fig. 1). Beer Sheva is $40 \mathrm{~km}$ north of Sede Boqer and Yotvata is $120 \mathrm{~km}$ south of Sede Boqer.

McClear estimates of $G, D, B$ and $B_{\mathrm{N}}$ for 10 min duration were obtained from the SoDa web site (www.soda-pro.com) for these same instants and for each location. It may be of interest here to underline that the McClear model computes $G$ and $B_{\mathrm{N}}$, then $B$, and that $D$ is deduced from $G-B$. Also provided were the corresponding time-series of the irradiance at the top of atmosphere on both horizontal and normal surfaces: $E_{0}$ and $E_{0 \mathrm{~N}}$. The clearness index $K T$ and the direct clearness index $K T_{B_{\mathrm{N}}}$ were computed for both measurements and McClear estimates using the following formula:

$$
\begin{aligned}
& K T=G / E_{0} \\
& K T_{B_{\mathrm{N}}}=B_{\mathrm{N}} / E_{0 \mathrm{~N}} .
\end{aligned}
$$


Table 2. Comparison between clear-sky global $G$ and diffuse $D$ SSI measured by ground stations and estimated by McClear. Units in $\mathrm{W} \mathrm{m}{ }^{-2}$.

\begin{tabular}{lccc|ccc}
\hline & \multicolumn{3}{c}{$G$} & & & $D$ \\
& BEE & SBO & YOT & BEE & SBO & YOT \\
\hline Mean observed SSI & 810 & 838 & 825 & 124 & 114 & 137 \\
Bias & 19 & 2 & 32 & 60 & 69 & 48 \\
Relative bias (\%) & 2 & 0 & 4 & 48 & 60 & 35 \\
RMSE & 32 & 30 & 41 & 66 & 74 & 55 \\
Relative RMSE (\%) & 4 & 4 & 5 & 53 & 65 & 40 \\
Squared correlation coefficient & 0.977 & 0.976 & 0.980 & 0.594 & 0.627 & 0.633 \\
\hline
\end{tabular}

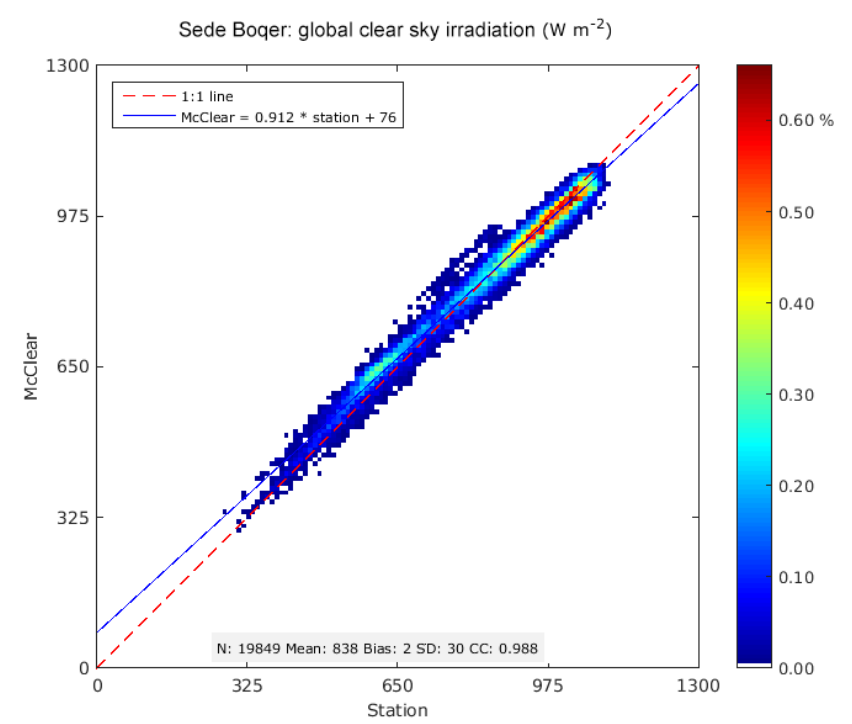

Figure 2. 2-D histogram of measurements (horizontal axis) and McClear estimates (vertical axis) of $G$ for Sede Boqer. The colour represents the frequency of each pair.

\section{Results}

Following the ISO (International Organization for Standardization) standard (1995), the deviations were computed by subtracting measurements for each instant from the McClear estimates and they were summarized by the bias, the root mean square error (RMSE), and the squared correlation coefficient, also known as the coefficient of determination $\left(R^{2}\right)$. Relative values are expressed with respect to the mean observed value. The validations of $K T$ and $K T_{B_{\mathrm{N}}}$ are also included, as they are stricter measures of the performance of a model with respect to the optical state of the atmosphere.

The 2-D histograms of measured and estimated values are presented for Sede Boqer (Figs. 2 and 3). Red, respectively dark blue, dots correspond to regions with great, respectively very low, densities of samples. The plots also present the number of samples, the mean reference value, the bias, the RMSE, the correlation coefficient (CC) and the $1: 1$ line $(y=x)$. One may see in Fig. 2 that the points are mostly

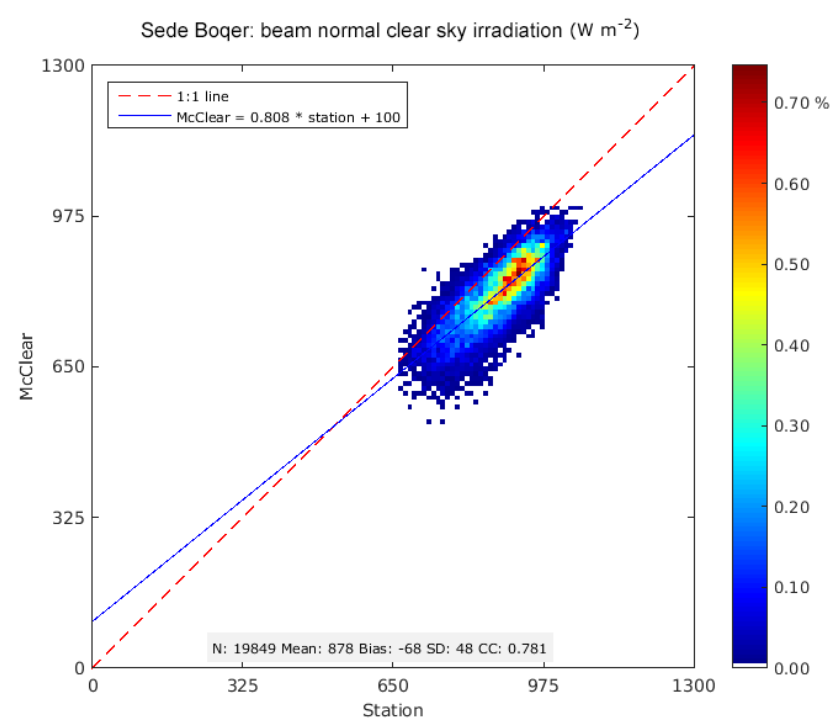

Figure 3. 2-D histogram of measurements (horizontal axis) and McClear estimates (vertical axis) of $B_{\mathrm{N}}$ for Sede Boqer. The colour represents the frequency of each pair.

aligned with the $1: 1$ line with a very limited scattering. The bias and RMSE are respectively 2 and $30 \mathrm{~W} \mathrm{~m}^{-2}$. The squared correlation coefficient is very large: 0.976 , meaning that the temporal changes in $G$ are well reproduced by McClear. The points in Fig. 3 for $B_{\mathrm{N}}$ are less aligned with the $1: 1$ line. The absolute value of the bias and RMSE are much larger: -68 and $83 \mathrm{~W} \mathrm{~m}^{-2}$. The squared correlation coefficient is 0.610 and a large amount of changes in $B_{\mathrm{N}}$ is unexplained by McClear.

Tables 2-4 present the results of the comparison for respectively $G, D, B, B_{\mathrm{N}}, K T$ and $K T_{B_{\mathrm{N}}}$. The means of $G$ (Table 2, approximately $830 \mathrm{~W} \mathrm{~m}^{-2}$ ), $B_{\mathrm{N}}$ (Table 3 , approximately $840 \mathrm{~W} \mathrm{~m}^{-2}$ ) and clearness indices (Table 4, 0.75 and $0.64)$ are large which means that the atmosphere is very often clear and not turbid. Yotvata experiences less $B_{\mathrm{N}}-$ and a lower $K T_{B_{\mathrm{N}}}$ - though it is the southernmost site. It is located $40 \mathrm{~km}$ north of the Red Sea in the Negev desert and may be under maritime influence and dust episodes. 
Table 3. Comparison between clear-sky beam SSI $B$ and beam at normal incidence $B_{\mathrm{N}}$ measured by ground stations and estimated by McClear. Units in $\mathrm{W} \mathrm{m}^{-2}$.

\begin{tabular}{lccc|ccc}
\hline & \multicolumn{3}{c}{$B$} & & \multicolumn{3}{c}{$B_{\mathrm{N}}$} \\
\hline & BEE & SBO & YOT & BEE & SBO & YOT \\
\hline Mean observed SSI & 686 & 724 & 688 & 841 & 878 & 809 \\
Bias & -41 & -66 & -16 & -46 & -68 & 13 \\
Relative bias (\%) & -6 & -9 & -2 & -6 & -8 & 2 \\
RMSE & 59 & 80 & 46 & 69 & 83 & 53 \\
Relative RMSE (\%) & 9 & 11 & 7 & 8 & 10 & 7 \\
Squared correlation coefficient & 0.931 & 0.937 & 0.929 & 0.576 & 0.610 & 0.603 \\
\hline
\end{tabular}

Table 4. Comparison between clear-sky clearness indices $K T$ and $K T_{B_{\mathrm{N}}}$ from ground stations and estimated by McClear.

\begin{tabular}{lccc|ccc}
\hline & \multicolumn{3}{c|}{$K T$} & & $K T_{B_{\mathrm{N}}}$ \\
\hline & BEE & SBO & YOT & BEE & SBO & YOT \\
\hline Mean observed index & 0.74 & 0.76 & 0.74 & 0.62 & 0.66 & 0.62 \\
Bias & 0.02 & 0.01 & 0.03 & -0.04 & -0.06 & -0.01 \\
Relative bias (\%) & 3 & 1 & 5 & -6 & -9 & -2 \\
RMSE & 0.03 & 0.03 & 0.05 & 0.05 & 0.07 & 0.04 \\
Relative RMSE (\%) & 5 & 4 & 6 & 8 & 11 & 7 \\
Squared correlation coefficient & 0.524 & 0.471 & 0.474 & 0.625 & 0.641 & 0.578 \\
\hline
\end{tabular}

The bias for $G$ is low for Sede Boqer: $2 \mathrm{~W} \mathrm{~m}^{-2}$, and is larger for the other sites: 19 and $32 \mathrm{~W} \mathrm{~m}^{-2}$, i.e. 2 and $4 \%$ of the mean observed $G$. The RMSE ranges from 30 to $41 \mathrm{~W} \mathrm{~m}^{-2}(4 \%)$ and the squared correlation coefficient is greater than 0.976 (Table 2). The influence of $\theta_{\mathrm{S}}$ on the SSI creates de facto a correlation between measurements and estimates in clear-sky conditions as $\theta_{\mathrm{S}}$ and $E_{0}$ can be accurately estimated. The influence of $\theta_{\mathrm{S}}$ on $K T$ is much less pronounced and the squared correlation coefficient denotes the ability of McClear to reproduce the optical state of the atmosphere. It ranges between 0.471 and 0.524 (Table 4) and is low. A majority of changes in $K T$ is not reproduced by McClear and improvements should be brought on the McClear model and on the quality of its inputs. The bias and RMSE for $K T$ are similar in relative value to those for $G$ (Table 4). Expectedly, the results for Sede Boqer are fully in line with the bias, RMSE and squared correlation coefficient for both $G$ and $K T$ reported by Lefèvre et al. (2013) for this station though for $1 \mathrm{~min}$ SSI: 7 and $30 \mathrm{~W} \mathrm{~m}^{-2}, 0.982$, and $0.01,0.03$ and 0.581 .

The estimates of $D$ by McClear are inaccurate (Table 2). There is an overestimation ranging between 48 and $69 \mathrm{~W} \mathrm{~m}^{-2}$ (35 to $60 \%$ of the mean of $D$ ). The RMSE ranges between 55 and $74 \mathrm{~W} \mathrm{~m}^{-2}$ (40 to $65 \%$ ). The squared correlation coefficient is comprised between 0.594 and 0.633 ; a large amount of changes in $D$ is unexplained by McClear.

An underestimation is observed for $B$ and $B_{\mathrm{N}}$ (Table 3), except Yotvata for $B_{\mathrm{N}}$. The bias for $B$, respectively $B_{\mathrm{N}}$, is comprised between -66 and $-16 \mathrm{~W} \mathrm{~m}^{-2}$, i.e. between -9 and $-2 \%$ of the mean $B$, and between -68 and $+13 \mathrm{~W} \mathrm{~m}^{-2}$ ( -8 and $2 \%$ of the mean $B_{\mathrm{N}}$ ). The RMSE ranges from $46(7 \%)$ to $80 \mathrm{~W} \mathrm{~m}^{-2}(11 \%)$ for $B$, and from $53(7 \%)$ to $83 \mathrm{~W} \mathrm{~m}^{-2}(10 \%)$ for $B_{\mathrm{N}}$. The bias and RMSE for $K T_{B_{\mathrm{N}}}$ are similar in relative value to those for $B$ and $B_{\mathrm{N}}$ (Table 4). The squared correlation coefficient for $B_{\mathrm{N}}$ and $K T_{B_{\mathrm{N}}}$ is close to 0.6 ; a large amount of changes in $B_{\mathrm{N}}$ or $K T_{B_{\mathrm{N}}}$ is unexplained by $\mathrm{McClear}$. The squared correlation coefficient for $B$ is much larger and close to 0.93 because of the influence of $\theta_{\mathrm{S}}$ on the correlation and the accuracy of its estimate.

An additional comparison was performed that dealt with the ability of McClear to reproduce spatial variability. The correlation coefficient between time-series of measurements, respectively McClear estimates, was computed for each pair of stations for $G$ and $B_{\mathrm{N}}$ (Table 5). It is observed (upper right part of the correlation matrix) that the measurements are very much correlated for $G$ (greater than 0.99), which can be explained by the fact that only clear-sky measurements are dealt with. The correlation coefficient is less for $B_{\mathrm{N}}$, especially between Yotvata and the two others for which it is respectively 0.630 and 0.728 . This is in agreement with the remoteness of Yotvata compared to the two others and the above remark on its climate.

The closer the correlation coefficients of the lower part of the matrix to those of the upper part, the more accurately McClear depicts the variability in space. The correlation coefficients for $G$ are almost identical for the measurements and McClear meaning that the actual SSI field is well reproduced by McClear. This is not the case for $B_{\mathrm{N}}$ for which discrep- 
Table 5. Correlation matrix between stations for measurements (upper right part of the matrix, in bold) and for McClear (lower left part, in italic) for $G$ and $B_{\mathrm{N}}$.

\begin{tabular}{lccc|cccc}
\hline$G$ & BEE & SBO & YOT & $B_{\mathrm{N}}$ & BEE & SBO & YOT \\
\hline BEE & 1 & $\mathbf{0 . 9 9 5}$ & $\mathbf{0 . 9 9 1}$ & BEE & 1 & $\mathbf{0 . 8 8 4}$ & $\mathbf{0 . 6 3 0}$ \\
SBO & 0.999 & 1 & $\mathbf{0 . 9 9 4}$ & SBO & 0.990 & 1 & $\mathbf{0 . 7 2 8}$ \\
YOT & 0.994 & 0.996 & 1 & YOT & 0.846 & 0.908 & 1 \\
\hline
\end{tabular}

ancies may be observed. There is an overestimation of the correlation by McClear which can be attributed to the correlation of its inputs due to the coarse spatial and temporal resolutions. CAMS products on aerosols and total content in water vapour and ozone are available every $3 \mathrm{~h}$. The spatial resolution is $1.125^{\circ}$, i.e. approx. $120 \mathrm{~km}$ along a longitude, for the aerosol properties. This is the same resolution for the total column content of ozone and water vapour before 2014 after which it became $0.8^{\circ}$. The $B_{\mathrm{N}}$ field estimated by McClear will be smoother than the actual field. Note that the ranking of the correlation coefficients is the same for both the measurements and McClear; the local extrema are respected though the intensity of the variation is decreased.

\section{Discussion and conclusion}

Like reported in other similar studies, the statistical quantities reported here vary with the period of analysis. A given quantity may change noticeably from one year to another. For example, the bias in $B_{\mathrm{N}}$ at Sede Boqer varies from -63 to $-75 \mathrm{~W} \mathrm{~m}^{-2}$ if years are considered separately. This indicates that care must be taken in the analysis of these quantities.

The quantities vary with the month. Trends are more or less marked. There is a tendency for lowest bias - in absolute value - and lowest RMSE in the period May-August. There is a tendency for the bias and the RMSE to increase with $\theta_{\mathrm{S}}$, yielding an increase - in absolute value - of the relative bias and RMSE as the mean $G$ and $B_{\mathrm{N}}$ decrease as $\theta_{\mathrm{S}}$ increases. Nevertheless, the changes are limited.

Eissa et al. (2015a, b) have performed similar studies but for respectively Egypt and the United Arab Emirates. Similarly to this study, Aswan and the UAE sites exhibit underestimation of $B_{\mathrm{N}}$. This underestimation is more pronounced for Beer Sheva and Sede Boqer. On the contrary, Yotvata exhibits an overestimation of $13 \mathrm{~W} \mathrm{~m}^{-2}$. The comparison of these different studies shows that the overall picture of the possible causes of the discrepancies between measurements and McClear estimates is still unclear. The underestimation in $B_{\mathrm{N}}$ may be partly caused by overestimation of the aerosol optical depth (AOD). Through comparisons between the AODs measured by AERONET and estimated in CAMS for desert areas in Egypt and UAE, Eissa et al. (2015b) and Oumbe et al. (2012) concluded that one main source of the errors in McClear originates from the CAMS AOD. Therefore, more accurate inputs to McClear would improve its estimates. For example, Oumbe et al. (2015) have shown that a local empirical correction of the CAMS AOD drastically decreases the bias in the United Arab Emirates.

As for $G$, if one looks at the results of Eissa et al. (2015a) for Aswan in Egypt - which is located in a desert far from the Cairo megapole, - one would observe that the large overestimation of $G$ by McClear over Aswan: $33 \mathrm{~W} \mathrm{~m}^{-2}$, is similar to that observed at Yotvata in this study. Yotvata exhibits the greatest bias of the three sites. The bias at Sede Boqer is $2 \mathrm{~W} \mathrm{~m}^{-2}$, expectedly similar to that of $7 \mathrm{~W} \mathrm{~m}^{-2}$ reported by Lefèvre et al. (2013) for the same site though for $1 \mathrm{~min}$ summarization. The bias for the more turbid sites in the UAE ranges from -5 to $10 \mathrm{~W} \mathrm{~m}^{-2}$.

Estimates in $G$ and $D$ - and hence the statistical performances - are sensitive to the type of aerosols that is estimated by the means of the empirical algorithm presented in Lefèvre et al. (2013) applied to the partial aerosol optical depths delivered by CAMS. It is found that in Beer Sheva and Sede Boqer - which are close compared to the size of the CAMS cell, - the most frequent aerosol type is "continental polluted", then "maritime polluted" and finally "desert". The same types are found for Yotvata but "desert" is most frequent than "maritime polluted". An error may arise if the wrong type is selected. Figure 1 in Lefèvre et al. (2013) displays a specific case of daily profile of $G$ in Carpentras (France) with a dramatic change by $30 \mathrm{~W} \mathrm{~m}^{-2}$ (approx. $3 \%$ ) due to an error in the empirical algorithm. In other cases reported in Eissa et al. (2015a) an overestimation of the fine, strongly scattering pollution particles associated with an underestimation of the coarse, less scattering, mineral dust particles would affect $G$ and $D$. It should be added that the coarse spatial and temporal resolutions of the CAMS data on aerosols make it difficult to capture the exact atmospheric effects on the incident solar radiation over a specific site. Other causes of uncertainty are the uncertainties in the OPAC model used in McClear (Lefèvre et al., 2013). Zieger et al. (2010) showed noticeable changes in single scattering albedo with relative humidity for the OPAC "continental polluted" and "maritime polluted" types. If relative humidity is assumed too large, then the single scattering albedo is overestimated, yielding an overestimation in $D$. This may explain the difference between the two sites Beer Sheva and Sede Boqer and the southern one Yotvata where "desert" is more frequent. Simulations performed with the radiative transfer model libRadtran have shown that in case of intense dust storms, i.e. heavy load in dust particles, the single scattering albedo in OPAC "desert" type underestimates that observed in AERONET measurements, which yields an underestimation in $D$. This is not observed in cases of low or medium loads in dust. This adds to the complexity as intense dust storms may also be observed in the northern sites.

Performances are still far from WMO standards: bias less than $3 \mathrm{~W} \mathrm{~m}^{-2}$ and $95 \%$ of the deviations less than $20 \mathrm{~W} \mathrm{~m}^{-2}$. Uncertainties in aerosol properties from CAMS are still too 
large, and more efforts are necessary for a better modelling of the aerosols.

Despite the identified drawbacks and paths for improvements, this validation of the McClear service for the desert conditions in Israel reveals satisfactory results. The comparisons between the McClear estimates and measurements of global horizontal and direct normal irradiances for 3 stations show that a large correlation is attained showing the ability of McClear to capture the temporal and spatial variability of the irradiance field. The performances are similar for the three sites for the global irradiance and for the DNI to a lesser extent, demonstrating the robustness of the CAMS McClear service.

Acknowledgements. The authors thank the Israel Meteorological Service, the operators of the BSRN Sede Boqer station for their valuable measurements and the Alfred-Wegener Institute for hosting the BSRN website. They also thank the anonymous referees whose comments helped in improving this paper. The research leading to these results has received funding from the European Union's Horizon 2020 Programme (H2020/2014-2020) under grant agreement no. 633081 (MACC-III project) and from the European Union's Copernicus Atmosphere Monitoring Service (CAMS).

Edited by: S.-E. Gryning

Reviewed by: two anonymous referees

\section{References}

Benedetti, A., Morcrette, J.-J., Boucher, O., Dethof, A., Engelen, R. J., Fisher, M., Flentje, H., Huneeus, N., Jones, L., Kaiser, J. W., Kinne, S., Manglold, A., Razinger, M., Simmons, A. J., and Suttie, M.: Aerosol analysis and forecast in the European Centre for Medium-Range Weather Forecasts Integrated Forecast System: 2. Data assimilation, J. Geophys. Res., 114, D13205, doi:10.1029/2008JD011115, 2009.

Blanc, P. and Wald, L.: The SG2 algorithm for a fast and accurate computation of the position of the Sun, Sol. Energy, 86, 30723083, doi:10.1016/j.solener.2012.07.018, 2012.

Eissa, Y., Korany, M., Aoun, Y., Boraiy, M., Abdel Wahab, M., Alfaro, S., Blanc, P., El-Metwally, M., Ghedira, H., and Wald, L.: Validation of the surface downwelling solar irradiance estimates of the HelioClim-3 database in Egypt, Remote Sensing, 7, 92699291, doi:10.3390/rs70709269, 2015a.

Eissa, Y., Munawwar, S., Oumbe, A., Blanc, P., Ghedira, H., Wald, L., Bru, H., and Goffe, D.: Validating surface downwelling solar irradiances estimated by the McClear model under cloudfree skies in the United Arab Emirates, Sol. Energy, 114, 17-31, doi:10.1016/j.solener.2015.01.017, 2015b.

GCOS - Global Climate Observing System Essential Climate Variables: available at: www.wmo.int/pages/prog/gcos/index.php? name=EssentialClimateVariables, last access: 20 February 2016.
ISO Guide to the Expression of Uncertainty in Measurement: first edition, International Organization for Standardization, Geneva, Switzerland, 1995.

Kaiser, J. W., Peuch, V.-H., Benedetti, A., Boucher, O., Engelen, R. J., Holzer-Popp, T., Morcrette, J.-J., Wooster, M. J., and the MACC-II Management Board: The pre-operational GMES Atmospheric Service in MACC-II and its potential usage of Sentinel-3 observations, ESA Special Publication SP708, Proceedings of the 3rd MERIS/(A)ATSR and OCLI-SLSTR (Sentinel-3) Preparatory Workshop, 15-19 October 2012, held in ESA-ESRIN, Frascati, Italy, 2012.

Lefèvre, M., Oumbe, A., Blanc, P., Espinar, B., Gschwind, B., Qu, Z., Wald, L., Schroedter-Homscheidt, M., Hoyer-Klick, C., Arola, A., Benedetti, A., Kaiser, J. W., and Morcrette, J.-J.: McClear: a new model estimating downwelling solar radiation at ground level in clear-sky conditions, Atmos. Meas. Tech., 6, 2403-2418, doi:10.5194/amt-6-2403-2013, 2013.

Oumbe, A., Bru, H., Hassar, Z., Blanc, P., Wald, L., Fournier, A., Goffe, D., Chiesa, M., and Ghedira, H.: Selection and implementation of aerosol data for the prediction of solar resource in United Arab Emirates, In Proceedings of SolarPACES Conference, 11-14 September 2012, Marrakech, Morocco, PSE AG, Freiburg, Germany, USBKey, Paper\#22240, 2012.

Oumbe, A., Qu, Z., Blanc, P., Lefèvre, M., Wald, L., and Cros, S.: Corrigendum to "Decoupling the effects of clear atmosphere and clouds to simplify calculations of the broadband solar irradiance at ground level" published in Geosci. Model Dev., 7, 1661-1669, 2014, Geosci. Model Dev., 7, 2409-2409, doi:10.5194/gmd-72409-2014, 2014.

Oumbe, A., Wald, L., Blanc, P., Ghedira, H., and Goffe, D.: Improving the solar resource estimation in the United Arab Emirates using aerosol and irradiance measurements, ISES Solar World Congress 2015, 8-12 November 2015, Daegu, Korea, 2015.

Percivall, G., Ménard, L., Chung, L.-K., Nativi, S., and Pearlman, J.: Geo-processing in cyberinfrastructure: making the web an easy to use geospatial computational platform, in: Proceedings, 34th International Symposium on Remote Sensing of Environment, Sydney, Australia, 10-15 April 2011, available at: www.isprs.org/proceedings/2011/ISRSE-34/ 211104015Final00671.pdf (last access: 1 March 2016), 2011.

Peuch, V.-H., Rouil, L., Tarrason, L., and Elbern, H.: Towards European-scale Air Quality operational services for GMES Atmosphere, 9th EMS Annual Meeting, EMS2009-511, 9th European Conference on Applications of Meteorology (ECAM) Abstracts, held 28 September-2 October 2009, Toulouse, France, 2009.

Roesch, A., Wild, M., Ohmura, A., Dutton, E. G., Long, C. N., and Zhang, T.: Corrigendum to "Assessment of BSRN radiation records for the computation of monthly means" published in Atmos. Meas. Tech., 4, 339-354, 2011, Atmos. Meas. Tech., 4, 973-973, doi:10.5194/amt-4-973-2011, 2011.

Zieger, P., Fierz-Schmidhauser, R., Gysel, M., Ström, J., Henne, S., Yttri, K. E., Baltensperger, U., and Weingartner, E.: Effects of relative humidity on aerosol light scattering in the Arctic, Atmos. Chem. Phys., 10, 3875-3890, doi:10.5194/acp-10-38752010, 2010. 